\title{
Optimal Power Control for Wind Turbine System based on the Simplified Fuzzy-PID Controller
}

\author{
Wang Xiangming ${ }^{1, a}$, Li Nan ${ }^{1, b, *}$ and Yang Jingshuai ${ }^{2, c}$ \\ ${ }^{1}$ Institute of Information Science and Engineering, Shenyang University of Technology, Tiexi Street, \\ Shenyang, China \\ ${ }^{2}$ Department of Detection Technology and Automation, Shenyang University of Technology, Tiexi \\ Street, Shenyang, China \\ aweisut@126.com, ${ }^{\mathrm{b}}$ linan163@163.com, ${ }^{\mathrm{c}} 1477885756 @$ qq.com \\ *corresponding author
}

Keywords: wind turbine, optimal power, simplified fuzzy-PID controller.

\begin{abstract}
The main objective of the paper is to implement controller design of large wind turbines. Specific focus is optimal power for variable speed turbines below rated wind speed. The paper adopts a simplified fuzzy-PID controller to realize for maximizing energy capture and optimizing power of wind turbine. The simplified fuzzy-PID control system reduces control rule and controls power of wind turbine efficiently. At the same time, it can realize for maximizing wind energy capture and controlling of wind turbine better than PID controller, and can make system more stable and reliable with comparison of PID controller.
\end{abstract}

\section{Introduction}

Wind energy is the fastest green energy. With the consumption of coal and petrolic, the gradual exhaustion of fossil energy and environmental pollution are becoming more serious, so people support to use clean energy to a higher degree. The use of wind energy has gained sizable progress[1].

It results in being more difficult to maximize wind energy because of the effect of randomness and the nonlinear of wind speed for wind turbine system, so maximizing wind energy has become the one of hot issues for study of wind power generation.

The literature[2] is controlling the pitch of wind turbine,rotor speed and generator power by using the method of increment PID that can adjust gain. So the method calculates increment only, if error or precision that the calculation produces is more low, it can't result in too large effect for controlled quantity. But this algorithm has its weakness, for instance it desen't have relevant correcting algorithm and obtains its gain adjustment sheet with difficulty. The literature[3] adopts synovial variable structure robust control for wind turbine system. It controls pitch angle and calculates coefficient matrix of switched function by the design method of linear feedback. Seen from simulation result, the approach has faster speed, smaller overshoot and better robust than PID 
controller in variational wind speed. The literature[4] adopts three controllers, the first one tracks generator speed,the second one controls generator magnetic flux to improve the efficiency of generator rectifier system in low wind speed, the last one controls the robust of system by controlling rotor speed.The literature[5] that is on the premise of known wind speed,adopts fuzzy control strategy to realize for maximizing wind speed and make system stable for variable speed and pitch wind turbine.Firstly when the literature [6] puts up variable speed and pitch wind turbine, and uses variable universe and self-adaption fuzzy controlling strategy to control rotor speed and pitch angle of generator.This strategy optimizes performance of wind turbine. The literature[7] imports rotor speed and power values,gets corresponding reference speed by fuzzy logical deduction system,controls electromagnetic torque by self-adaption optimal fuzzy control of nearest neighbor cluster study method and gains optimum tip speed ratio and realizes for maximizing wind speed.

The paper adopts a simplified fuzzy-PID controller to optimize and control 1.5MW-wind turbine.Maximizing wind speed for variable wind turbine system(such as double-fed induction machine and permanent magnet synchronous generator)gets more attention for realizing high efficiency at wind energy transition system[8-10].

Control and simulation of the paper is based on permanent magnet synchronous generator model. The PMSM is always used generally because of its simple structure,easy maintain,stable and durable features. Nevertheless, all kinds of factors in generator have grievous coupling and nonlinear feature,they can create difficulty for upper limit time and day-to-day control of generator.We don't need precise mathematical model based on fuzzy control system with nonlinear and artificial intelligent characters[11-12]. And fuzzy control system has better robust and adaptability than PID control system.But accuracy of PID controller is higher than fuzzy controller.So the paper realizes power control of wind turbine system by using a simplified fuzzy-PID controller.

The total scheme of this article: D-value of tip speed ratio is input as fuzzy-PID controller when wind turbine operates under rated wind speed.And then we build wind turbine model by MATLAB/Simulink.Finally, it can maximize wind speed,optimize and control power for wind turbine.

\section{Wind Turbine System}

\subsection{The Strategy for Wind Turbine Control System}

The paper adopts control scheme of wind turbine system in Fig.1, the sketch is as follows: firstly, wind turbine produces rotor speed when wind speed inputs into wind turbine, then the D-value of tip speed ratio $\lambda$ by calculation and reference tip speed ratio $\lambda *$ is input as controller, and then wind turbine realizes for optimizing and controlling power by fuzzy-PID controller. Control system of wind turbine simulator platform is as shown in Fig.1.

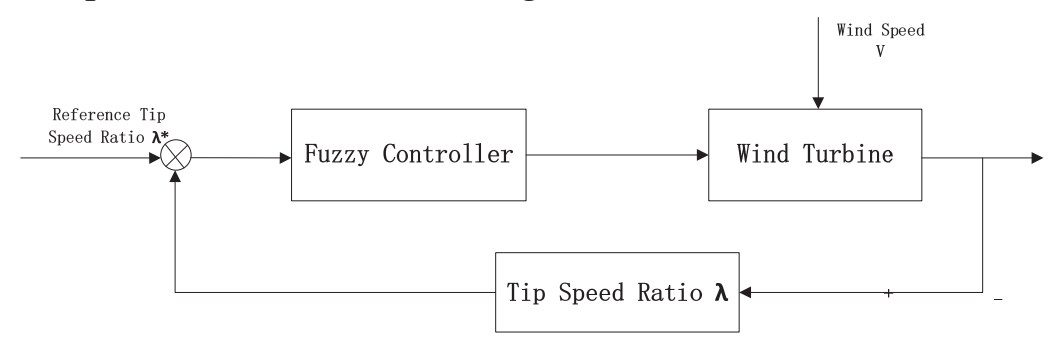

Fig.1 The control system of wind turbine simulator platform. 


\subsection{The Basic Theory of MPPT Method}

MPPT method makes wind energy power that wind turbine absorbs and transforms reach maximum value in any rated wind speed [13].

Mechanical power for the wind turbine can be written as:

$$
P=\frac{1}{2} \rho \pi R^{2} C_{p}(\lambda, \beta) V^{3}
$$

Where $P$ is output power of wind turbine, $\rho$ is air density, the value is $1.225 \mathrm{~kg} / \mathrm{m}^{3}, \mathrm{R}$ is the rotor radius and $35.25 \mathrm{~m}, \mathrm{C}_{\mathrm{p}}$ is wind energy transform coefficient, $\mathrm{V}$ is wind speed.

Actually, the efficiency that wind turbine transforms wind energy into mechanical energy varies with respect to $C_{p}$ and $C_{p}$ is function about tip speed ratio $\lambda$ and blade pitch angle $\beta$, they are as follow:

$$
\begin{array}{r}
C_{p}=0.22\left(\frac{116}{\lambda_{\mathrm{i}}}-0.4 \beta-5\right) \mathrm{e}^{\frac{-12.5}{\lambda_{\mathrm{i}}}} \\
\lambda_{\mathrm{i}}=\frac{1}{\lambda+0.08 \beta}-\frac{0.035}{\beta^{3}+1} \\
\lambda=\frac{\omega_{\mathrm{r}} \mathrm{R}}{\mathrm{V}}=\frac{\pi \mathrm{Rn}}{30 \mathrm{v}}
\end{array}
$$

Where $\omega_{\mathrm{r}}$ is turbine speed in $\mathrm{rad} / \mathrm{s}, \mathrm{n}$ is rotor speed in $\mathrm{rpm} / \mathrm{m}$. Therefore, wind turbine gains how much power with respect to $\mathrm{C}_{\mathrm{p}}$ only.

The paper discusses the second section where wind turbine operates in, blade pitch angle remains unchanged in this phase. When $\beta$ remains unchanged, the typical relation that is between $C_{p}$ and $\lambda$ is shown as Fig.2.

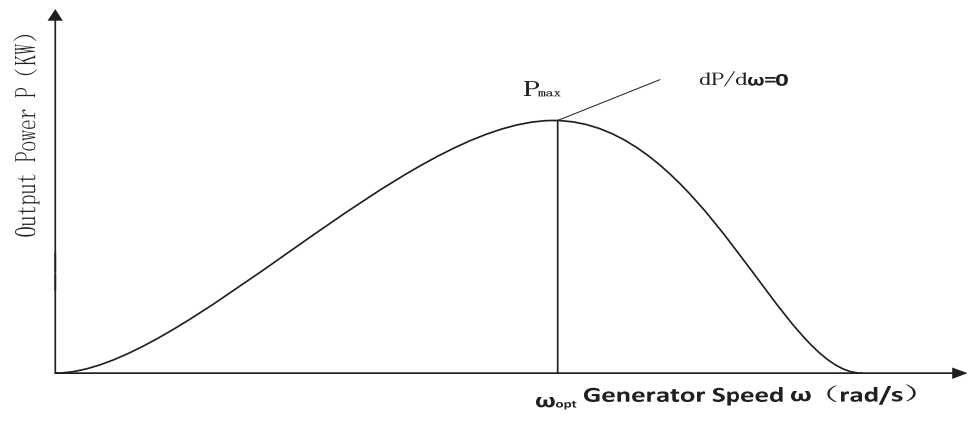

Fig. 2 The $\mathrm{C}_{\mathrm{p}}-\lambda$ relative curve.

\section{The Design of Fuzzy-PID Controller}

\subsection{The Fuzzy-PID Control System}

The fuzzy-PID controller is named as self-tunning PID controller. It adopts fuzzy logical inference method to adjust parameters of PID control algorithm. The result that is reasoned by fuzzy inference isn't as the output of system, and then the systematic output is decided according to PID algorithm [14]. 


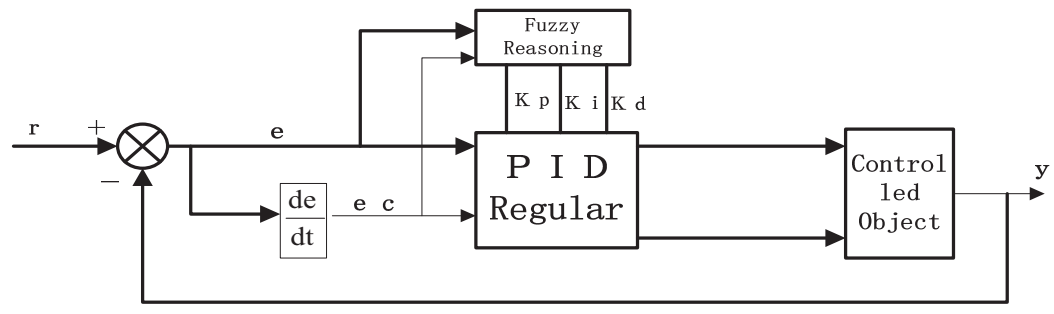

Fig.3 The fuzzy-PID control system.

As shown in Fig.3,the fuzzy-PID control system includes 4 parts: feed-forward PID, error e, error ratio ec and fuzzy part including $\mathrm{K}_{\mathrm{e}}, \mathrm{K}_{\mathrm{ee}}$, fuzzy inference and proportion part of output control variable quantity. When the error value is in a small range, the part of feed-forward PID is effective and is easy to void the steady state error and improves the system sensitivity at the load disturbance.

\subsection{The Simplified Fuzzy-PID Controller}

\subsubsection{The Derivation of Simplified Fuzzy-PID Controller}

As shown in Fig.4, both of error e and error rate ec are input variation of simplified fuzzy-PID controller, the output control variation is $\mathrm{u} . \mathrm{E} \subset \mathrm{R}, \mathrm{E} \subset \mathrm{R}, \mathrm{U} \subset \mathrm{R}$ are theory of discrete domain of e,ec,u,the fuzzy set of $e$ and ec is $A_{i}(i \in I=[-m, \ldots,-2,-1,0,1,2, \ldots m])$ and $B_{j}(j \in J=$ $[-\mathrm{n}, \ldots,-2,-1,0,1,2 \ldots \mathrm{n}])$ respectively. According to the literature [15], the fuzzy control rule is as follows :

If $e$ is $A_{i}$ and ec is $B_{j}$ then $u$ is $u_{i j}$.

$u_{i j} \in U(i \in I, j \in J)$ is fixed value.

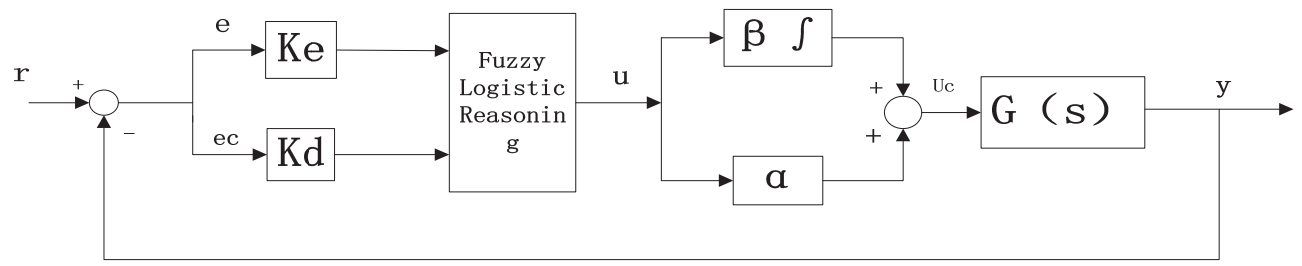

Fig.4 The Schematic diagram of Simplified fuzzy-PID.

$\mathrm{A}_{\mathrm{i}}$ (e) and $\mathrm{B}_{\mathrm{j}}$ (ec) are the membership function, and they are triangle function. According to reasoning method of product sum and the focus of the solution of fuzzy method, the true value of forward fuzzy-PD controller can be calculated:

The output of fuzzy-PD controller is as shown:

$$
f_{i j}=A_{i}(e) B_{j}(e c) \quad(i \in I, j \in J)
$$

$$
\mathrm{u}=\frac{\sum_{\mathrm{i}, \mathrm{j}} \mathrm{f}_{\mathrm{ij}} \mathrm{u}_{\mathrm{ij}}}{\sum_{\mathrm{i}, \mathrm{j}} \mathrm{f}_{\mathrm{ij}}}=\frac{\sum_{\mathrm{i}, \mathrm{j}}\left(\mathrm{A}_{\mathrm{i}}(\mathrm{e}) \mathrm{B}_{\mathrm{j}}(\mathrm{ec})\right) \mathrm{u}_{\mathrm{ij}}}{\sum_{\mathrm{i}, \mathrm{j}}\left(A_{\mathrm{i}}(\mathrm{e}) \mathrm{B}_{\mathrm{j}}(\mathrm{ec})\right)}
$$

Now, if it works at $t$ time, the range of input variable of fuzzy controller is $\left[\mathrm{e}_{i}, \mathrm{e}_{\mathrm{i}+1}\right]$, the scope of ec is $\left[\mathrm{ec}_{j}, \mathrm{ec}_{j+1}\right]$, the core of fuzzy subset of $A_{i}$ and $A_{i+1}$ are $e_{i}$ and $e_{i+1}$, but the core of fuzzy subset of $B_{j}$ and $B_{j+1}$ are $e c_{j}$ and $e c_{j+1}$,it is as shown in Fig.5. 

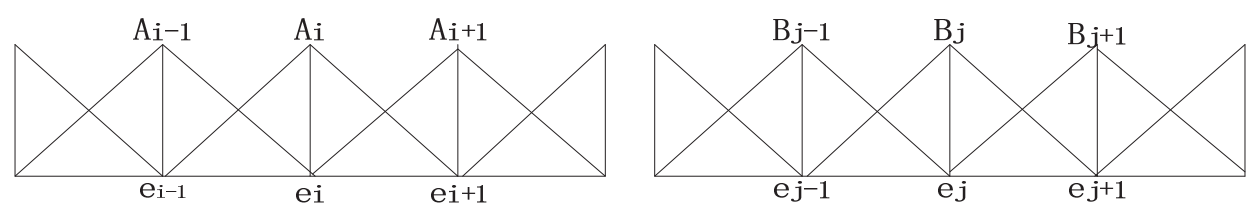

Fig.5 The membership functions of $A_{i}$ and $B_{j}$.

The membership functions of e and ec at some time are indicated respectively:

$$
\begin{aligned}
A_{i}(e) & =1-\frac{e-e_{i}}{e_{i+1}-e_{i}}=\frac{e_{i+1}-e}{e_{i+1}-e_{i}} A_{i+1}(e)=\frac{e-e_{i}}{e_{i+1}-e_{i}} \\
A_{i+1}(e) & =\frac{e-e_{i}}{e_{i+1}-e_{i}} B_{j}(e c)=1-\frac{e c-e c_{j}}{e c_{j+1}-e c_{j}}=\frac{e c_{j+1}-e c}{e c_{j+1}-e_{j}} B_{j+1}(e c)=\frac{e c-e c_{j}}{e c_{j+1}-e c_{j}}
\end{aligned}
$$

As is known in Fig.5, the situation that the membership function of e and ec are unequal to zero is only on two neighboring fuzzy subset, as follows:

$$
A_{k}(e)=0\left(k \neq(i, i+1) \in I \quad B_{j+1}(e c)=0(t \neq(j, j+1) \in J)\right.
$$

Therefore, the equation (6) can be simplified as:

$$
\begin{aligned}
& \sum_{\mathrm{k}=(\mathrm{i}, \mathrm{j}+1)} \quad\left(\mathrm{A}_{\mathrm{k}}(\mathrm{e}) \mathrm{B}_{\mathrm{t}}(\mathrm{ec})\right) \mathrm{u}_{\mathrm{ij}} \\
& \mathrm{u}=\frac{\mathrm{t}=(\mathrm{j}, \mathrm{j}+1)}{\sum_{\mathrm{k}=(\mathrm{i}, \mathrm{j}+1)}\left(\mathrm{A}_{\mathrm{k}}(\mathrm{e}) \mathrm{B}_{\mathrm{t}}(\mathrm{ec})\right)}
\end{aligned}
$$

When $e \in\left[e_{i}, e_{i+1}\right]$, there is $A_{i}(e)+A_{i+1}(e)=1$,

When ec $\in\left[\mathrm{ec}_{\mathrm{j}}, \mathrm{ec}_{\mathrm{j}+1}\right]$, there is $\mathrm{B}_{\mathrm{j}}(\mathrm{e})+\mathrm{B}_{\mathrm{j}+1}(\mathrm{e})=1$,

So, the denominator of the equation (7) is

$\sum_{k=(i, j+1)}\left(A_{k}(e) B_{t}(e c)\right)=A_{i}(e) B_{j}(e c)+A_{i+1}(e) B_{j}(e c)+A_{i}(e) B_{j+1}(e c)+A_{i+1}(e) B_{j+1}(e c)=$ $\mathrm{t}=(\mathrm{j}, \mathrm{j}+1)$

$\left(A_{i}(e)+A_{i+1}(e)\right) \quad\left(B_{j}(e)+B_{j+1}(e)\right)=1$

And then, the equation can be simplified further:

$\mathrm{u}=$

$\sum_{k=(i, j+1)}\left(A_{k}(e) B_{t}(e c)\right) u_{i j}=A_{i}(e) B_{j}(e c) u_{i j}+A_{i+1}(e) B_{j}(e c) u_{(i+1) j}+A_{i}(e) B_{j+1}(e c) u_{i(j+1)}+$ $\mathrm{t}=(\mathrm{j}, \mathrm{j}+1)$

$A_{i+1}(e) B_{j+1}(e c) u_{(i+1)(j+1)}=$

$\left(\frac{e_{i+1}-e}{e_{i+1}-e_{i}}\right)\left(\frac{e c_{j+1}-e c}{e c_{j+1}-e c_{j}}\right) u_{i j}+\left(\frac{e-e_{i}}{e_{i+1}-e_{i}}\right)\left(\frac{e c_{j+1}-e c}{e c_{j+1}-e c_{j}}\right) u_{(i+1) j}+\left(\frac{e_{i+1}-e}{e_{i+1}-e_{i}}\right)\left(\frac{e c-e c_{j}}{e c_{j+1}-e c_{j}}\right) u_{i(j+1)}+$

$\frac{\mathrm{e}-\mathrm{e}_{\mathrm{i}}}{\mathrm{e}_{\mathrm{i}+1}-\mathrm{e}_{\mathrm{i}}} \frac{\mathrm{ec}-\mathrm{ec} \mathrm{ec}_{\mathrm{j}}}{\mathrm{ec}_{\mathrm{j}+1}-\mathrm{ec} \mathrm{c}_{\mathrm{j}}} \mathrm{u}_{(\mathrm{i}+1)(\mathrm{j}+1)}$

Where e $\in\left[\mathrm{e}_{\mathrm{i}}, \mathrm{e}_{\mathrm{i}+1}\right], \mathrm{ec} \in\left[\mathrm{ec}_{\mathrm{j}}, \mathrm{ec}_{\mathrm{j}+1}\right]$.

It is seen as in equation (9), the nonlinear function of e and ec are fuzzy controller output, its definition is:

$\mathrm{u}=\mathrm{f}(\mathrm{e}, \mathrm{ec})$

For above a series of linear problems, they can be solved by small deviation linearization technique, it is defined as:

$$
\begin{array}{r}
\delta_{\mathrm{e}}=\mathrm{e}-\mathrm{e}_{\mathrm{i}} \\
\delta_{\mathrm{ec}}=\mathrm{ec}-\mathrm{ec}_{\mathrm{j}} \\
\delta_{\mathrm{u}}=\mathrm{u}-\mathrm{u}_{\mathrm{ij}}
\end{array}
$$

If $\delta_{e}, \delta_{e c}$ and $\delta_{u}$ are enough small and $\left(\mathrm{e}_{\mathrm{i}}+\delta_{\mathrm{e}}, \mathrm{ec}_{\mathrm{j}}+\delta_{\mathrm{ec}}\right) \in\left[\mathrm{e}_{\mathrm{i}}, \mathrm{e}_{\mathrm{i}+1}\right] \times\left[\mathrm{ec}_{\mathrm{j}}, \mathrm{ec}_{\mathrm{j}+1}\right]$, the equation (10) can be approximated according to following linear equation:

$\delta_{\mathrm{u}}=\left[\frac{\partial \mathrm{f}}{\partial \mathrm{e}}\right]_{\left(\mathrm{e}_{\mathrm{i}}, \mathrm{ec} \mathrm{j}\right)} \delta_{\mathrm{e}}+\left[\frac{\partial \mathrm{f}}{\partial \mathrm{ec}}\right]_{\left(\mathrm{e}_{\mathrm{i}}, \mathrm{ec}_{\mathrm{j}}\right)} \delta_{\mathrm{ec}}$ 
(9) is as follows:

$\left[\frac{\partial \mathrm{f}}{\partial \mathrm{e}}\right]_{\left(\mathrm{e}_{\mathrm{i}}, \mathrm{ec} \mathrm{c}_{\mathrm{j}}\right)}=\frac{\mathrm{u}_{(\mathrm{i}+1) \mathrm{j}}-\mathrm{u}_{\mathrm{ij}}}{\mathrm{e}_{\mathrm{i}+1}-\mathrm{e}_{\mathrm{i}}}$
$\left[\frac{\partial \mathrm{f}}{\partial \mathrm{ec}}\right]_{\left(\mathrm{e}_{\mathrm{i}}, \mathrm{ec} \mathrm{e}_{\mathrm{j}}\right)}=\frac{\mathrm{u}_{\mathrm{i}(\mathrm{j}+1)}-\mathrm{u}_{\mathrm{ij}}}{\mathrm{ec_{j+1 } - \mathrm { ec } _ { \mathrm { j } }}}$

So, there is

$\delta_{u}=u-u_{i j}=\frac{u_{(i+1) j}-u_{i j}}{e_{i+1}-e_{i}}\left(e-e_{i}\right)+\frac{u_{i(j+1)}-u_{i j}}{e c_{j+1}-e c_{j}}\left(e c-e c_{j}\right)$

And then:

$u=\left(u_{i j}-\frac{u_{(i+1) j}-u_{i j}}{e_{i+1}-e_{i}} e_{i}-\frac{u_{i(i+1)}-u_{i j}}{e c_{j+1}-e c_{j}} e c_{j}\right)+\frac{u_{(i+1) j}-u_{i j}}{e_{i+1}-e_{i}} e+\frac{u_{i(j+1)}-u_{i j}}{e c_{j+1}-e c_{j}} e c=A+P e+D e c$

In the equation:

$$
\begin{array}{r}
A=u_{i j}-\frac{u_{(i+1) j}-u_{i j}}{e_{i+1}-e_{i}} e_{i}-\frac{u_{i(i+1)}-u_{i j}}{e c_{j+1}-e c_{j}} e c_{j}=u_{i j}-P e_{i}-D e c_{j} \\
P=\frac{u_{(i+1) j}-u_{i j}}{e_{i+1}-e_{i}} D=\frac{u_{i(j+1)}-u_{i j}}{e c_{j+1}-e c_{j}}
\end{array}
$$

As follows in the above, it can infer the output of simplified fuzzy-PID controller in Fig.4:

$\mathrm{u}_{\mathrm{c}}=\alpha \mathrm{u}+\beta \int \mathrm{udt}=\alpha\left(\mathrm{A}+\mathrm{Pk}_{\mathrm{e}} \mathrm{e}+\mathrm{Dk}_{\mathrm{d}} \mathrm{ec}\right)+\beta \int\left(\mathrm{A}+\mathrm{Pk}_{\mathrm{e}} \mathrm{e}+\mathrm{Dk} \mathrm{k}_{\mathrm{d}} \mathrm{ec}\right) \mathrm{dt}=\alpha \mathrm{A}+\beta \mathrm{At}+$ $\left(\alpha \mathrm{k}_{\mathrm{e}} \mathrm{P}+\beta \mathrm{k}_{\mathrm{d}} \mathrm{D}\right) \mathrm{e}+\beta \mathrm{k}_{\mathrm{e}} \mathrm{P} \int \mathrm{edt}+\alpha \mathrm{k}_{\mathrm{d}}$ Dec $\quad(15)$

From (15), the relation between input and output in whole fuzzy controller is a simple and timevarying relation of proportion-integral-differential, the proportionality coefficient is $\alpha k_{e} P+\beta k_{d} D$, the integral coefficient is $\beta \mathrm{k}_{\mathrm{d}} \mathrm{D}$, the differential coefficient is $\alpha \mathrm{k}_{\mathrm{e}} \mathrm{P}$.

\subsubsection{The Fuzzy Variation of Input and Output and Rule Function}

The fuzzy controller has two inputs and one output. The input variable is difference value of tip speed ratio e and variable rate ec, output variable is $\mathrm{u}$. e, ec and u that changed into fuzzy variable are E,EC and U.E, they include \{Small, Middle Small, Small Small, Zero-, Zero+, Small Big, Middle Big, Big $\} 8$ fuzzy subsets, all of language variable can be expressed as $\{$ S,MS,SS,Z$, \mathrm{Z}+, \mathrm{SB}, \mathrm{MB}, \mathrm{B}\}$,the range is [-30,30]. EE includes \{Small, Middle Small, Small Small, Zero, Small Big, Middle Big, Big\}, 7 fuzzy subsets, the expression of language variable is $\{\mathrm{S}, \mathrm{MS}, \mathrm{SS}, \mathrm{Z}, \mathrm{SB}, \mathrm{MB}, \mathrm{B}\}$, the range is $[-6,6] . \mathrm{U}$ includes $\{$ Small, Middle Small, Small Small, Zero, Small Big, Middle Big, Big\} 7 fuzzy subsets, the expression of language variable is $\{\mathrm{S}, \mathrm{MS}, \mathrm{SS}, \mathrm{Z}, \mathrm{SB}, \mathrm{MB}, \mathrm{B}\}$,the range is $[0,1]$.The rule function is as follows in Fig.6.

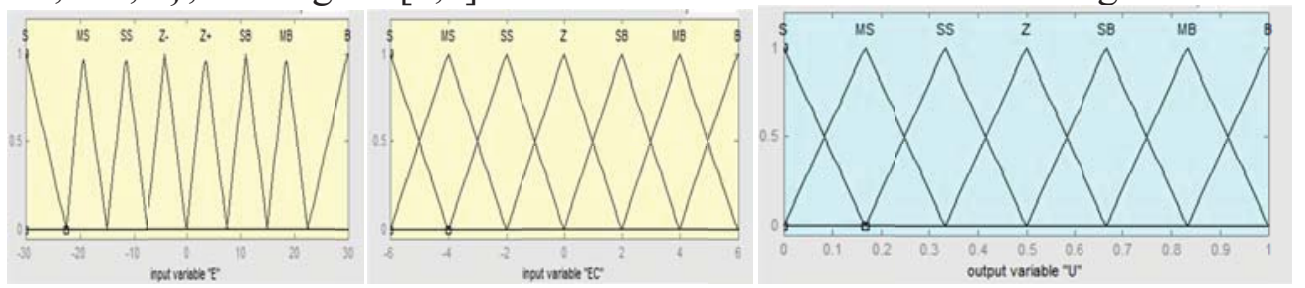

Fig.6 The Membership function distributing of input E,EC and output U.

\subsubsection{Fuzzy control rule and strategy}

The fuzzy control rules get from actual control experience. The rule that the paper adopts is:

$\mathrm{R}_{\mathrm{i}}$ : if $\mathrm{E}_{\mathrm{i}}$ and $\mathrm{EE}_{\mathrm{i}}$ then $\mathrm{U}_{\mathrm{i}}$

The fuzzy inference adopts Mamdani method, defuzzy adopts the center area method. The whole fuzzy control rules gain from rules, inference method and fuzzy variable of input and output. As follows in Table 1. 
Table1 Rules Table of Fuzzy Control.

\begin{tabular}{|c|c|c|c|c|c|c|c|c|}
\hline ec & S & MS & SS & Z- & Z+ & SB & MB & B \\
\hline S & S & S & MS & SS & Z & MB & MB & B \\
\hline MS & S & S & MS & SS & Z & MB & MB & B \\
\hline SS & S & S & MS & SS & SB & MB & B & B \\
\hline Z & S & S & MS & SS & SB & MB & B & B \\
\hline SB & S & S & MS & SS & SB & MB & B & B \\
\hline MB & S & MS & MS & Z & SB & MB & B & B \\
\hline B & S & MS & SS & Z & MS & MB & B & B \\
\hline
\end{tabular}

\section{The modelling and simulation of wind turbine}

The wind turbine has three subsystems including aerodynamic model, transmission system model and generator model.

1. The aerodynamic model

The power that the blades absorb is as shown in (1).

The equation of aerodynamic model is:

$\mathrm{J}_{\mathrm{r}}=\frac{\mathrm{d} \omega_{\mathrm{r}}}{\mathrm{dt}}=\mathrm{T}_{\mathrm{r}}-\mathrm{nT}_{\mathrm{m}}$

Where $\mathrm{J}_{\mathrm{r}}$ is Moment of inertia of rotor, $\omega_{\mathrm{r}}$ is blade angle speed, $\mathrm{T}_{\mathrm{r}}$ is blade aerodynamic torque, $\mathrm{n}$ is growth gearbox transmission ratio, $\mathrm{T}_{\mathrm{m}}$ is the axis of rotation to the rigid shaft torque.

The relation is between transmission ratio and power:

$\mathrm{T}_{\mathrm{r}}=\frac{\mathrm{P}}{\omega_{\mathrm{r}}}=\frac{1}{2} \rho \pi \mathrm{R}^{2} \mathrm{C}_{\mathrm{p}}(\lambda, \beta) \frac{v^{3}}{\omega_{\mathrm{r}}}$

2. The transmission system model

Because the connection between blade and gear box speeder is rigid, so this paper neglects overall force of friction in drive system and relative displacement of output shaft.

3. The math model of generator

This paper adopts permanent magnet synchronous generator, the equation of the math model of generator is:

$\mathrm{T}_{\mathrm{e}}=\frac{\mathrm{pm}_{1} \mathrm{U}_{1}{ }^{2} \mathrm{r}_{2}}{\left(\omega_{\mathrm{g}}-\omega_{\mathrm{r}}\right)\left[\left(\mathrm{r}_{1}-\frac{\mathrm{C}_{1} \mathrm{r}_{2} \omega_{1}}{\omega_{\mathrm{g}}-\omega_{1}}\right)^{2}+\left(\mathrm{x}_{1}+\mathrm{C}_{1} \mathrm{x}_{2}\right)^{2}\right]}$

Where $T_{e}$ is the counter torque of generator, $p$ is the generator number of polo-pairs, $m_{1}$ is the stator voltage of generator, $\mathrm{U}_{1}$ is network voltage, $\mathrm{C}_{1}$ is correction factor, $\omega_{\mathrm{g}}$ is generator rotation velocity, $\omega_{1}$ is synchronous speed of generator, $r_{1}, \mathrm{x}_{1}$ are resistance and leakage reactance of statorwinding, $\mathrm{r}_{2}, \mathrm{x}_{2}$ are corrected rotor winding and leakage reactance. The generator rotating equation is:

$\mathrm{J}_{\mathrm{g}} \frac{\mathrm{d} \omega_{\mathrm{g}}}{\mathrm{dt}}=\mathrm{T}_{\mathrm{m}}-\mathrm{T}_{\mathrm{e}}$ 
Where $J_{g}$ is rotational inertia of generator, $T_{e}$ is generator counter torque, $T_{m}$ is torque that axis of rotation transmit to rigid gear.

\section{Conclusions}

The wind turbine model with simplified fuzzy-PID controller is as follows in Fig.7.

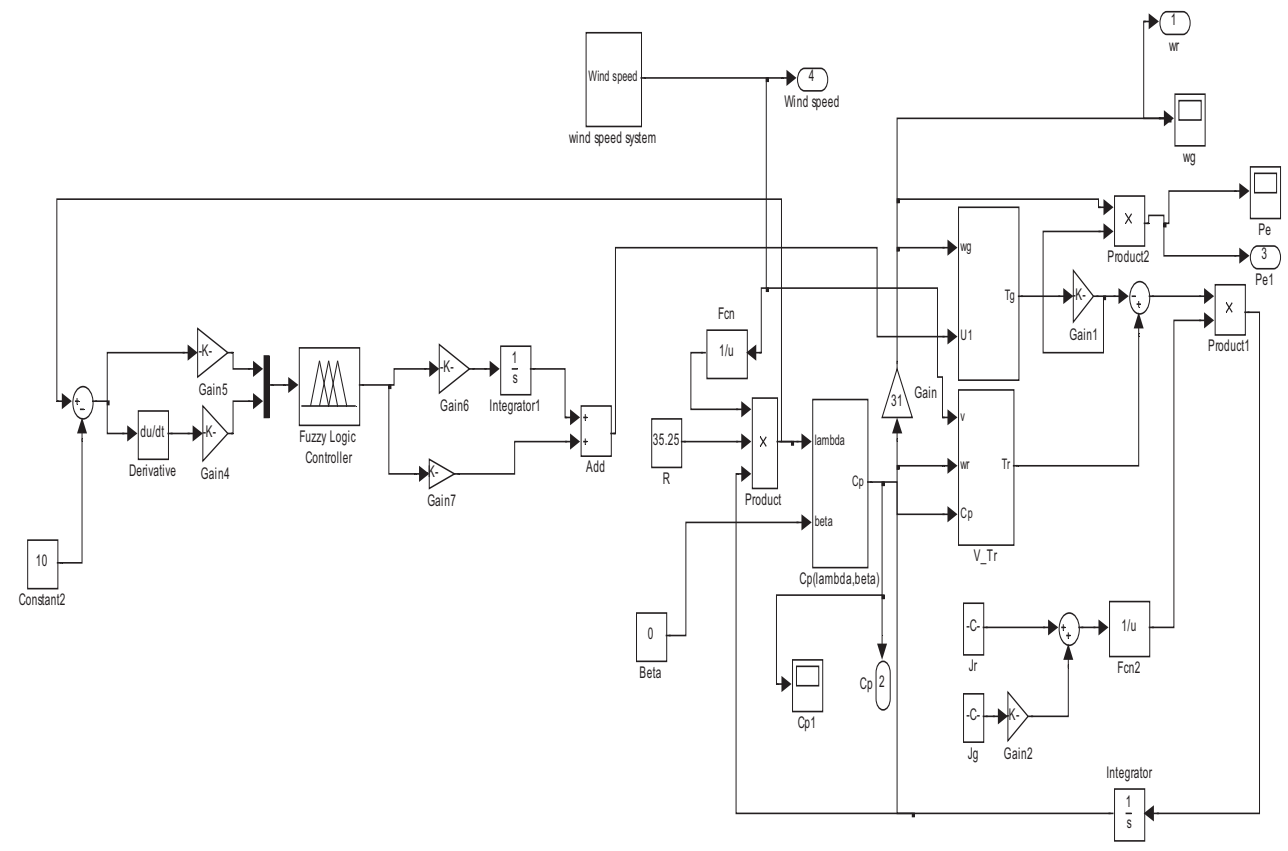

Fig.7 The Simulation System of Wind Turbine with Simplified Fuzzy-PID Controller.

1. The comparison of the simplified fuzzy-PID control system and PID control system of wind turbine under rated wind speed is as shown in Fig.8 -Fig.10.

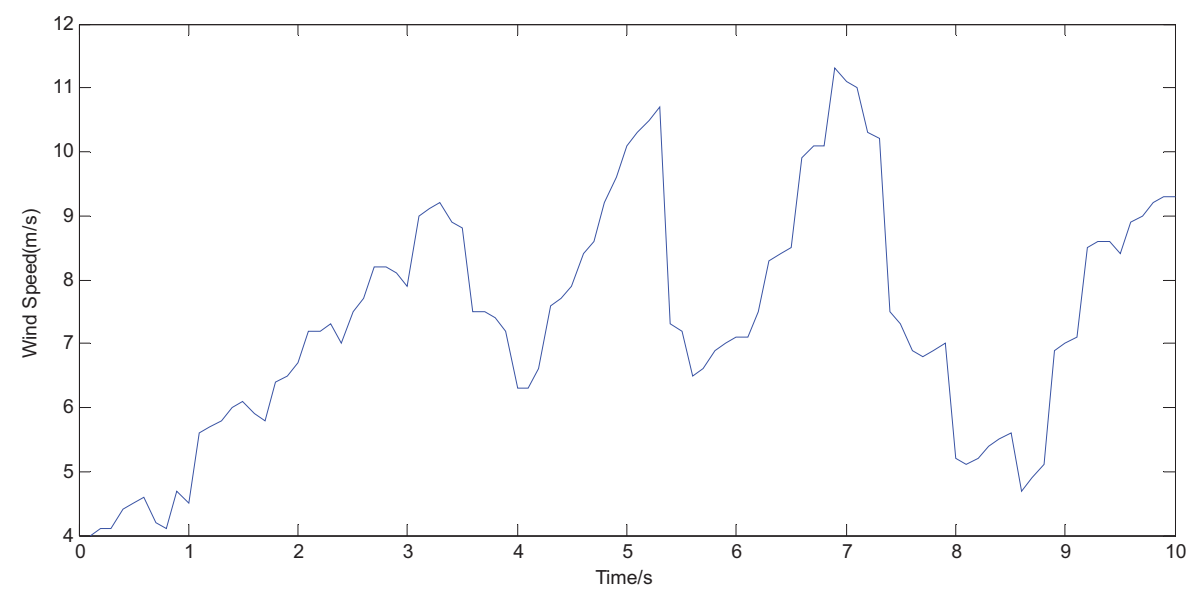

Fig8. The simulation of different rated wind speed. 


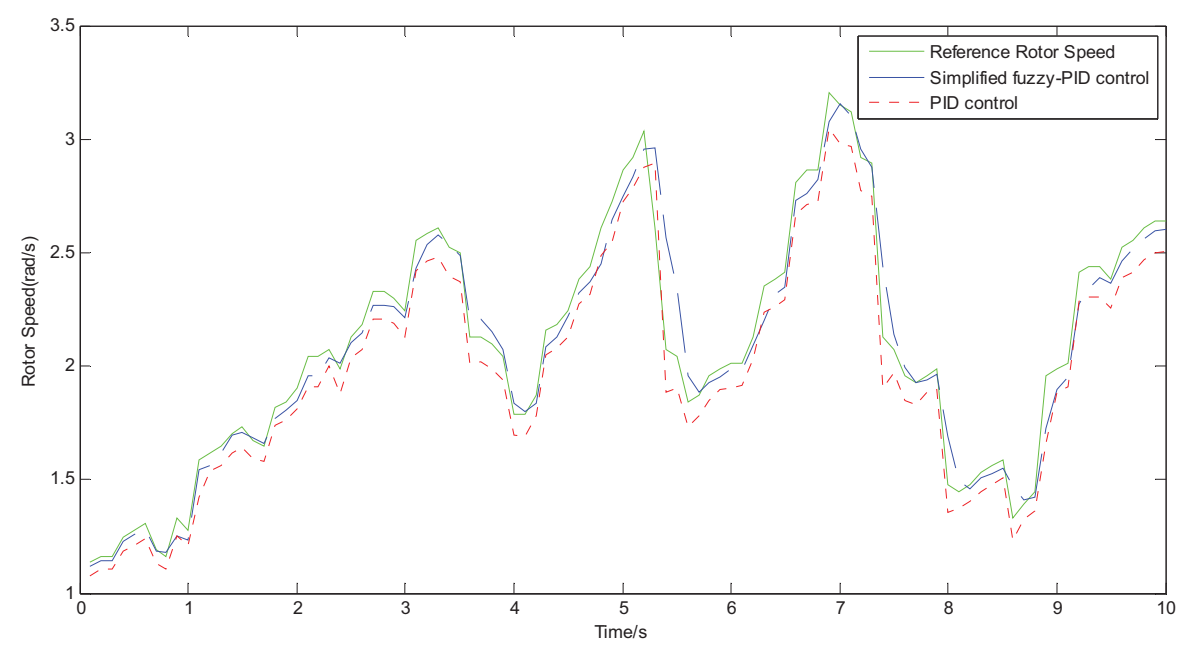

Fig9. The comparison diagram of rotor speed simulation below rated wind speed.

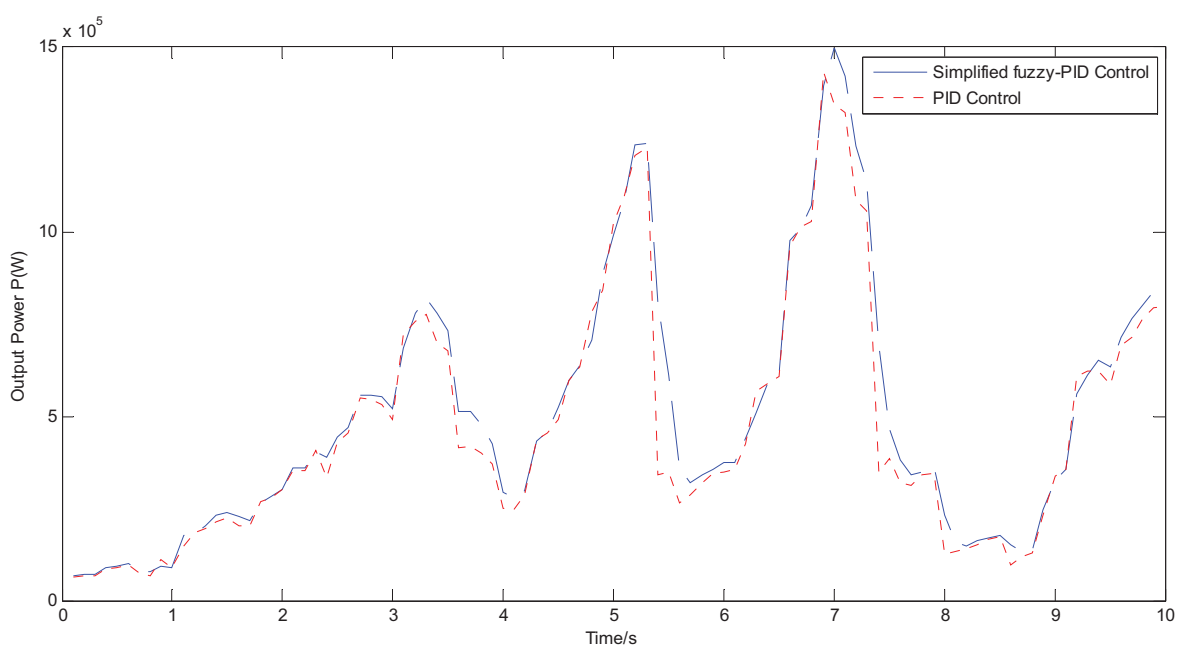

Fig10. The comparison diagram of output power simulation.

2. The theoretical values of wind turbine system are gained by calculating, when wind speed is $6 \mathrm{~m} / \mathrm{s}$. Respectively, $C_{p}$ is 0.44374 , rotor speed is $1.702 \mathrm{rad} / \mathrm{s}$, output power is $229.058 \mathrm{kw}$. The comparison of simplified fuzzy-PID controller and PID controller with no controller about the error. The results are as shown in Table2-Table4.

Table 2. The error comparison of power coefficient.

\begin{tabular}{|c|c|c|}
\hline & Power Coefficient $\mathrm{C}_{\mathrm{p}}$ & Theoretical error(\%) \\
\hline The simplified fuzzy-PID control & 0.43415 & 2.161 \\
\hline PID control & 0.41551 & 6.362 \\
\hline
\end{tabular}

Table 3. The error comparison of rotor speed $\omega$.

\begin{tabular}{|c|c|c|}
\hline & Rotor Speed $\omega(\mathrm{rad} / \mathrm{s})$ & Theoretical error(\%) \\
\hline The simplified fuzzy-PID control & 1.695 & 0.425 \\
\hline PID control & 1.617 & 5.000 \\
\hline
\end{tabular}


Table 4. The error comparison of output power P.

\begin{tabular}{|c|c|c|}
\hline & Output Power P(kw) & Theoretical error(\%) \\
\hline The simplified fuzzy-PID control & 232.573 & 1.535 \\
\hline PID control & 214.480 & 6.364 \\
\hline
\end{tabular}

3. The simplified fuzzy-PID control system that the paper adopts doesn't simplify fuzzy control rules but improves speed and accuracy of wind turbine efficiently. The paper analyses the control situation of PID controller and simplified fuzzy-PID controller in different wind speed. Simultaneously, the simulation in specific wind speed makes a comparison, the result indicates fuzzy-PID control system can gain bigger power and has smaller oscillation, smaller steady-state error and better steady-state performance than PID control system.

\section{References}

[1] Leung DYC, Yang Y. (2012) Wind energy development and its environmental impact: a review. Renew Sustain Energy Rev 16(1):103-104,.

[2] Zhang Le, Jin Shangtai.( 2006)Large wind generator control simulation study[J]. CHINA SCIENCE AND TECHNOLOGY INFORMATION.

[3] Guo Qingding, Zhao Lin, Guo Honhche(2005) 1MW The robust control of sliding mode variable structure for a variable speed variable pitch wind turbine[J]. Shenyang University of Technology Journal, 27 (2) :171-174,.

[4] Anastasios I. Dounis, Panagiotis Kofinas(2013)Adaptive fuzzy gain scheduling PID controller for maximum power point tracking of photovoltaic system[J], Renewable Energy, 202-214.

[5] Mao Hsiung Chiang(2011) A novel pitch control system for a wind turbine driven by a variable-speed pumpcontrolled hydraulic servo system [J]. Mechatronics, 21: 753-761.

[6] ZHANG Xinfang, XU Daping(2004)Adaptive Fuzzy Control for Large-scale Variable Speed Wind Turbines[J]. JOURNAL OF SYSTEM SIMULATION. Vol. 16 No.

[7] CHEN Jiawei, CHEN Jie, CHEN Ran(2011) Adaptive Fuzzy Logic Control Technique for Variable-speed Wind Turbines[J]. Proceedings of the CSEE, Vol.31 No.21.Jul.25.

[8] H. Li and Z. Chen(2008)Overview of different wind generator systems and their comparisons, IET Renew. Power Gen., vol. 2, no. 2, 123-138.

[9] S. Soterand R. Wegener(2007) Development of induction machines in wind power technology, in Proc. IEEE Int. Elect. Mach. Drives Conf., Antalya, Turkey, 1490-1495.

[10] J. A. Baroudi, V. Dinavahi, and A. M. Knight(2005) A review of power con-Int. Conf. Elect. Mach. Drives. IEEE, verter topologies for wind generators, in Proc 458-465.

[11] M. Namazov, R. Samet, R. Huseynov(2007), Modeling and Simulation of the Fuzzy Relay Type Controller for Solving the Double Integrator Control Problems[C], Proceedings of the 9th WSEAS International Conference on Automatic Control, Modeling \& Simulation.

[12] Samir Nejim, NawelTej, Naceur Benhadj Braiek(2007)Robust Quadratic Stabilization for a Class of Discrete-time Nonlinear Uncertain Systems: A Genetic Algorithm Approach. Proceedings of the 9th WSEAS International Conference on Automatic Control, Modeling \& Simulation.

[13] Kazmi, S.M.R., Goto, H, Guo, H. J., etal(2010) Review and critical analysis of the research papers published till date on maximum power point tracking in wind energy conversion system, Proc. IEEE Energy Conversion Congress and Exposition (ECCE), 4075-4082.

[14] Linus, R.M., Damodharan, P.(2012) Maximum power point tracking and grid feeding of permanent magnet synchronous generator based wind energy conversion system using modified hill climb searching algorithm. IEEE Fifth India Int. Conf. on Power Electronics (IICPE),1-3.

[15] Yishuang Qi, Qingjin Meng(2012) The Application of Fuzzy PID Control in Pitch Wind Turbine[C]. International Conference on Future Energy, Environment, and Materials, Energy Procedia 16:1635 - 163. 